\title{
Embedding a culture of academic integrity: A two-pronged approach
}

\author{
Mercedez Hinchcliff, Pranit Anand \\ University of Wollongong, Queensland University of Technology
}

\begin{abstract}
While universities have instituted use of various forms of technologies to help identify instances of academic integrity compromises, these tools are unable to detect cases where students get someone else to do their academic work for them. This paper discusses a two-stage approach to addressing academic integrity at a postgraduate business studies course where students were engaged in understanding what academic integrity means within their context and explore various forms of unethical behaviours. They were also made aware about various institutional policies and procedures for academic integrity breaches. This was followed with a post-assessment, ad-hoc feedback from students about their submitted work. Although a thorough evaluation is planned at a later stage, this paper shares some initial results about the effectiveness of this approach to countering academic misconduct behaviours. The paper will be of interest to other teaching academics interested in developing a culture of academic integrity.
\end{abstract}

Keywords: Academic integrity, assessments, feedback, academic misconduct

\section{Introduction}

Assessments play an important role in higher education. While there are arguments about the validity of many forms of assessments, they continue to provide a valuable measure to educators about student's levels of understanding of the material, and therefore help decisions about progression and awarding of qualifications. Unfortunately, the confidence in many assessment scores is challenged due to increasing incidents of academic integrity compromises (Bretag, 2020). It has become easier for students to gain access to work that has been done by others, and even more concerning is the trend towards 'contract cheating'. Contract cheating is where students engage someone else to do the assessments for them.

Academic misconduct and various forms of unethical academic behaviours poses a significant challenge for educators. While various technological tools such as 'Turnitin' may help detect when students plagiarise and use the work of others, it is incapable of detecting the increasing forms of contract cheating. In fact, an entire business model is growing around this type of service where 'expert' writers engage in 'contracts' to write assessments for students (Bretag, Harper, Burton, Ellis, Newton, Rozenberg, Saddiqui, \& van Haeringen, 2019). These types of academic misconduct are difficult for academic integrity technology tools to detect.

The reasons why students engage in these unethical behaviours are wide and varied, however one of the ideas often put forward is that if students are motivated to learn, that is, not merely interested in grades, then they are far less likely to engage in unethical academic behaviours (Day, Hudson, Dobies, \& Waris, 2011). Additionally, studies suggest that student engagement and motivation to learn are often a deterrent to these behaviours used concurrently with awareness about the repercussions of unethical conduct (Rundle, Curtis, \& Clare, 2020).

\section{Embedding a culture of integrity}

Like other types of academic behaviours such as ways of learning, teaching and assessments, academic integrity tends to be a part of the culture within institutions (Dawson, Bearman, Boud, Hall, Molloy, Bennett, \& Joughin, 2013). Students engage with all forms of teaching and learning initiatives within the embedded cultural expectations of their institutions. Similarly high trusting institutions often have strategies in place to ensure this trust is demonstrated and expect similar from students. Therefore, studies have shown that the incident of academic misconduct tends to be higher among first-year university students than students in later years of their studies (Ellis, van Haeringen, Harper, Bretag, Zucker, McBride, Rozenberg, Newton, \& Saddiqui, 2020). For students still being 'inducted' into institutional expectations and cultures, explicit initiatives should be undertaken to allow them to become aware about the expectations, but significantly explicit instructions to allow 
students to learn about ethical academic behaviours and consequences for breaches.

The following strategies were embedded in a large business course at a regional university.

\section{Engaging students in ethical practices and formal writing}

Tutorial/workshop time is essential to use the theoretical principles learned in the lectures and apply them to general practice. Although this time is valuable to cover subject matter, it is just as important to pause and discuss ethical practices and formal writing. Engaging students early in this discussion also alleviates time and energy when marking assessments later. Studies have indicated that if students are engaged in a conversation about ethical behaviours they are less likely to engage in unethical behaviours such as contract cheating (Rundle, Curtis, \& Clare, 2020).

In a first-year postgraduate marketing class the entire first workshop is dedicated to ethical practices and formal writing. By doing this early on, students are empowered with the knowledge of their expectations early on which is another detractor of cheating (Bertram Gallant, 2017).

In the workshop, students listen to a presentation and watch videos on how to search for peer reviewed journal articles, best practices, how to reference properly and the difference between summarising and plagiarism. As an activity to discuss summarising, students are told to find a partner and to discuss the last movie they watched. The students will actively converse during this activity. Once all the students have finished discussing the movies, the instructor reveals what they have just summarised. They are asked to do the same for their written assessments. Students should read an article or chapter, understand it, and then write their understanding of it in their own words whilst still acknowledging where they obtained the information from.

Next, the students are given an excerpt from a journal article (Marketing sourced). They are asked to summarise the journal article into a single paragraph in a formal tone and give correct in-text referencing. They are given quick feedback after they submit the summary from the instructor which provides them with encouragement that they are on the right track and understand the expectations of the class.

Lastly, they are given an academic integrity quiz on Moodle. The quiz has nine multiple choice questions taken from the material of the earlier presentation and a reflection question at the end. Although this quiz does not count towards their overall marks for the subject, the students must receive $100 \%$ to obtain access to their future quizzes (which are counted towards their overall mark). The reflection question asks the students to state what academic integrity means to them and how they will use integrity in their future assessments.

\section{Post-assessment feedback/reflection}

Various plagiarism detection technology tools such as 'Turnitin' and others are good at identifying the possibility of plagiarism for work that has been done by students. However, with the increase in contract cheating, unethical behaviour can be harder to detect. There is a growing industry that entice students to engage in these unethical behaviours and many are becoming extremely good at providing these services. Educators often must rely on their own intuition to identify cases of contract cheating.

Many times, after students would submit written assessments, questions surrounding the legitimacy of writing would come up. It is challenging for academics to question their student's integrity simply based on a 'hunch' To circumvent such uncomfortable situations, a post-assessment feedback and reflection was developed. In a postgraduate marketing class, one of the main items of assessment is to create a marketing plan. This marketing plan is around 2,000 words in length and must be submitted via 'Turnitin' on their Moodle page. Turnitin does a wonderful job of detecting copied text, but one of its limitations is the ability to find purchased papers that is contract cheating.

A simple way of detecting any potential contract cheating is ask students, after the assessment has been submitted, to complete a post-assessment feedback and reflection in real-time during class (du Rocher, 2020). The reflection is not marked, rather provides teachers with a quick and easy way to verify if the student has done the work themselves. Some examples of the type of questions include:

- What was the name of the organisation you selected for the marketing plan?

- What were some of the things you admired about this organisation?

- What did you find most difficult about this assessment?

- What did you enjoy most about this assessment? 
For the students who wrote the assessment themselves, teachers received valuable insights to their assessment task. For those students who did not write the report themselves, the answers would clearly indicate the lack of understanding of the assessment task and could be used as support in discussing contract cheating allegations with the student.

\section{Discussion}

First year students can be overwhelmed in the beginning of their studies (Nelson, Creagh, Kift, \& Clarke, 2014). Many are starting their postgraduate journeys in a different culture or have been out of academia for some time. By taking the time early in the subject to spend one-on-one time with students in a workshop situation, empowers students to higher achievement through a greater understanding of expectations of not only the subject itself, but the overall course.

Whilst formal results have not been gathered yet, there is a clear reduction in suspected cheating using these methods semester upon semester. The feedback from students after the first workshop is positive and students are thankful for the seminar. This method also works well in an online setting and can be done virtually using the same techniques.

Using the post-assessment evaluation form, students who contract cheated were able to be (mostly) identified if they were unable to answer the post-assessment reflection questions effectively. As an example, students who cheated could not answer simple questions such as "who the organisation selected was?". This creates further deterrence to cheat in the future. Although this method does not guarantee every student who contract cheats is caught, it has been successful in many cases. Additionally, this approach encourages ethical behaviour by increasing awareness about acceptable standards. If the students anticipate the post assessment feedback, they may read the assessment they purchased. However, if this is the case then the student is likely to have learned at least some aspect of the material and this could be another positive taken from the exercise. An evaluative exercise is planned to these initiatives to see to what extent this has impacted student's attitudes towards academic integrity.

\section{Conclusion}

By engaging students early on in the subject, about ethical behaviour and formal academic writing whilst relating it to the subject matter and tasks, students feel empowered in the subject and are more prepared for their assessments. Understanding the consequences of unethical behaviours early in the subject can be a distractor for students to cheat. Additionally, using a post-assessment evaluation not only gives an instructor critical information regarding the design of the assessment task, but also provides an easier way to detect contract cheating.

\section{References}

Ally, M. (Ed.). (2009). Mobile Learning: Transforming the Delivery of Education and Training. Athabasca University Press. https://www.aupress.ca/books/120155-mobile-learning/

Bannister, B., Cornish, L., Bannister-Tyrrell, M., \& Gregory, S. (2015). Creative us of digital technologies: Keeping the best and brightest in the bush. Australian and International Journal of Rural Education, 25(1), 52-65.

Beetham, H., \& Sharpe, R. (Eds.). (2013). Rethinking Pedagogy for a Digital Age: Designing for 21st Century Learning (2nd ed.). Routledge Taylor \& France Group. doi:10.4324/9780203961681

Bower, M., Cram, A., \& Groom, D. (2010). Blended reality: Issues and potentials in combining virtual worlds and face-to-face classes. In C. H. Steel, M. J. Keppell, P. Gerbic, \& S. Housego (Eds.), Curriculum, technology \& transformation for an unknown future - Proceedings of the 27th ASCILITE Conference (pp. 129-140). The University of Queensland. https://www.ascilite.org/conferences/sydney10/procs/Bower-full.pdf

Bretag, T. (2020). A Research Agenda for Academic Integrity. Cheltenham, UK: Edward Elgar Publishing.

Bretag, T., Harper, R., Burton, M., Ellis, C., Newton, P., Rozenberg, P., . . van Haeringen, K. (2019). Contract cheating: a survey of Australian university students. Studies in higher education (Dorchester-onThames), 44(11), 1837-1856. doi:10.1080/03075079.2018.1462788

Bertram Gallant, T. (2017). Academic Integrity as a Teaching \& Learning Issue: From Theory to Practice. Theory Into Practice: Theoretical Approaches to Understanding and Promoting Academic Integrity, 56(2), 88-94. doi:10.1080/00405841.2017.1308173 
Dawson, P., Bearman, M., Boud, D., J. , Hall, M., Molloy, E., K. , Bennett, S., \& Joughin, G. (2013). Assessment Might Dictate the Curriculum, but What Dictates Assessment? Teaching \& Learning Inquiry: The ISSOTL Journal, 1(1), 107-111. doi:10.20343/teachlearninqu.1.1.107

Dalgarno, B., Hedberg, J., Harper, B., Williamson, A., Gunn, C., Young, A., \& Clear, T. (2002). The contribution of $3 D$ environments to conceptual understanding. 149-158. https://www.ascilite.org/conferences/auckland02/proceedings/papers/051.pdf

Day, N., Hudson, D., Dobies, P., \& Waris, R. (2011). Student or situation? Personality and classroom context as predictors of attitudes about business school cheating. Social Psychology of Education, 14(2), 261-282. doi:10.1007/s11218-010-9145-8

du Rocher, A. R. (2020). Active learning strategies and academic self-efficacy relate to both attentional control and attitudes towards plagiarism. Active Learning in Higher Education, 21(3), 203-216. doi: $10.1177 / 1469787418765515$

Ellis, C., van Haeringen, K., Harper, R., Bretag, T., Zucker, I., McBride, S., . . Saddiqui, S. (2020). Does authentic assessment assure academic integrity? Evidence from contract cheating data. Higher Education Research \& Development, 39(3), 454-469. doi:10.1080/07294360.2019.1680956

Herrington, J. (2006). Authentic e-learning in higher education: Design principles for authentic learning environments and tasks. In T. Reeves \& S. Yamashita (Eds.), Proceedings of World Conference on ELearning in Corporate, Government, Healthcare, and Higher Education 2006 (pp. 3164-3173).

Kearsley, G., \& Shneiderman, B. (1998). Engagement theory: A framework for technology-based teaching and learning. Educational Technology, 38(5), 20-23.

Nelson, K. J., Creagh, T., Kift, S. M., \& Clarke, J. A. (2014). Transition Pedagogy Handbook : A Good Practice Guide for Policy and Practice in the First Year Experience at QUT.

Rundle, K., Curtis, G., \& Clare, J. (2020). Why students choose not to cheat. In T. Bretag (Ed.), A Research Agenda for Academic Integrity. Cheltenham, UK: Edward Elgar Publishing.

Salmon, G. (2000). E-Moderating: The Key to Teaching and Learning Online. Kogan Page.

Hinchcliff, M., \& Anand, P. (2021). Embedding a culture of academic integrity: A two-pronged approach. In Gregory, S., Warburton, S., \& Schier, M. (Eds.), Back to the Future - ASCILITE '21. Proceedings ASCILITE 2021 in Armidale (pp. 304-307). https://doi.org/10.14742/ascilite2021.0143

Note: All published papers are refereed, having undergone a double-blind peer-review process.

The author(s) assign a Creative Commons by attribution licence enabling others to distribute, remix, tweak, and build upon their work, even commercially, as long as credit is given to the author(s) for the original creation.

(C) Hinchcliff, M., Anand, P. 2021 